\title{
English Translation of Construction Text: Illogic Expressions and the Application of Explication Strategy
}

\author{
Shukun Zhang, Peiying Guo \\ School of Arts and Science, Shaanxi University of Science and Technology, Xi'an, China \\ Email: 844646254@qq.com
}

How to cite this paper: Zhang, S. K., \& Guo, P. Y. (2019). English Translation of Construction Text: Illogic Expressions and the Application of Explication Strategy. Open Journal of Modern Linguistics, 9, 229-237.

https://doi.org/10.4236/ojml.2019.94021

Received: July 1, 2019

Accepted: August 13, 2019

Published: August 16, 2019

Copyright $\odot 2019$ by author(s) and Scientific Research Publishing Inc. This work is licensed under the Creative Commons Attribution International License (CC BY 4.0).

http://creativecommons.org/licenses/by/4.0/

\begin{abstract}
The accuracy of English translation of construction texts ensures the implementation of cooperative projects with foreign parties. However, translators are prone to comprehension errors in the process of English translation, thus leading to illogic expressions in the target text. This paper first analyzes the illogic expression problems at lexical, syntactical and discourse level, then briefly introduces explication translation strategy. Finally, it proposes explication translation strategy in construction texts so as to achieve the effect of precise wording, concise expression and rigorous logic.
\end{abstract}

\section{Keywords}

Construction Text, Illogic Expressions, Explication Translation Strategy

\section{Introduction}

Construction text describes the construction activities in each stage of the project implementation. Currently, China has made more and more cooperation with the countries along the "Belt and Road" in engineering construction. For the communication between the cooperation parties, all the construction documents have to be translated into English. However, due to the differences between English and Chinese thinking mode, grammatical application and expression habits, translators tend to ignore the cohesion between logical chains in English translation, resulting in illogic expressions, which leads to errors in information transmission, misunderstandings among construction personnel, and even accidents during engineering construction.

A series of studies have been carried out by scholars in the field of translation to solve the problem of illogic expressions. Duan Yimin demonstrated that there 
will be illogic expressions during information delivering from the aspects of close connection and interaction restriction between logic and language expression (Duan, 2004). On this basis, Wu Dilong demonstrated the correction method of illogic expressions from five aspects: common sense of life, discourse awareness, professional knowledge, grammatical analysis and meaning comprehension ( $\mathrm{Wu}, 2015)$. Some scholars, such as Xi Chunsheng and Gu Qingsong, have discussed the application of explication translation strategy from the aspect of logical relation (Xi, 2008; Gu, 2015).

This paper analyzed the causes of the illogic expressions and its manifestations in construction texts, and proposes to use explication translation strategy for avoiding illogic expressions.

\section{Illogic Expressions in Construction Texts}

Logical thinking is an indirect and generalized reaction process to the objective world by using rational cognitive forms such as concepts, judgments and reasoning (Fang, 2011). Logical thinking in English writing is embodied in the absence of ambiguity, accurate information transmission, and clear structure. However, illogic expression is a process contrary to the above, that is, logic chain breaks (Wu, 2015).

There are various reasons for the illogic expressions. Objectively, natural language has certain fuzziness, which is one of the inevitable reasons. At the same time, there are differences in thinking mode, grammatical application and expression habits between English and Chinese. English "pays attention to explicit cohesion, sentence form, and structural integrity, and shows meaning by form; Chinese, on the other hand, pays attention to implicit coherence, time and order of events, function and meaning, and uses meaning to serve form" (Lian, 2010). Based on this, the "implicit coherence" in Chinese, that is, "words and clauses are not connected by linguistic means, and the grammatical meaning and logical relation are expressed by the meaning of words or clauses" (Lian, 2010), has caused the difference in the logical expression forms of the two languages, resulting in illogic expressions in the process of English translation, while the social and cultural differences between the two languages make the linguistic differences more obvious. Subjectively, the uncertainty of the translator's cognitive ability and transformation ability for transforming implicit logic in Chinese intensifies the occurrence of illogic expressions.

As a guiding document, construction texts are characterized by directive and explicit features, thus achieving the basic purpose of transmitting information. According to Katharina Reiss's summary of the characteristics of different text types, information text is content-based and its main function is to exchange information and knowledge. The language means of transmitting information is logic or referential meaning (Li, 2012). However, due to subjective and objective reasons, logic chain, as one of the language means to transmit information, is prone to be broken in the process of language transformation, i.e. unclear ex- 
pression, deviation from the logical structure of the target language and lack of logic. According to linguistic features of the construction text, this paper analyzes the illogic expressions in the process of English translation. On this basis, an overview of the manifestations of illogic expressions from lexical, syntactical and discourse level is given, so as to accurately use explication translation strategy to make up the broken logic chain.

\subsection{Illogic Expressions at Lexical Level}

As a scientific and technological style, the vocabulary of construction texts is characterized by "strict organization" and "formal wording", and technical words and semi-technical words are frequently used. The application of common words in the field of construction texts is relatively accurate, indicating the professionalism and accuracy of such texts. Due to the professionalism of technical words, the exact corresponding words can be used during English translation, thus illogic expressions are mostly manifested in the professionalization process of semi-technical words and common words. For example, “基础设计” is wrongly translated as "basic design". The word “设计” here focuses on the planning of the engineering process rather than the design process. The use of the word "design" ignores the meaning of the construction process, resulting in illogic expressions. The form of illogic expressions at the lexical level is thus manifested as improper vocabulary selection in the translated text, ignoring the dynamic meaning of the text.

\subsection{Illogic Expressions at Syntactic Level}

Construction texts aim to describe the scheme and design information objectively. Therefore, most sentences have the characteristics of conciseness. Moreover, in order to highlight the strong command and expressiveness, non-subject sentences often used in Chinese construction texts for expressing imperative or prohibition, and their subjects are relatively implicit or directly omitted to conform to the Chinese expression habit. For example, as a construction plan, the non-subject sentence “钩铲退挖时不得伤及原有锥坡防护结构” is concise and clear, which can effectively convey the information. However, the grammatical components of subject, predicate and object in English are the main expression mode, and the lack of subject in the original text results in illogic expressions in the translation process. Therefore, the error in the choice of subject of the sentence is also one of the manifestations of illogic expressions in construction texts.

\subsection{Illogic Expressions at Textual Level}

Short sentences are often used in Chinese construction text, which is characterized by refined information and implicit logical relations, so as to achieve the effect of clear and concise information transmission. However, the combination of the features and English expressions, which focus on logical connection, has resulted in illogic expressions. Its main manifestations are lack of logical rela- 
tions such as causal relation, comparison relation and progressive relation.

Generally speaking, the phenomenon of illogic expressions in construction texts is manifested as ambiguity, vague expression and lack of logic, which cannot achieve the purpose of accurately conveying information.

\section{Introduction of Explication Translation Strategy}

According to Katharina Reiss's theory on the translation methods of informative texts, translation should convey all the referential content or conceptual content of the source text, and the translation should be "plain prose", without nonsense, and the meaning of the source text should be made explicit when necessary ( $\mathrm{Li}$, 2012). In view of the manifestations of the above illogic expressions in construction texts, this paper proposes to use explication strategy to make up the broken logic chain in texts and clarify the logic of texts so that the target text can meet the basic requirements of accurately conveying information.

Explication is also commonly referred to as explicitation, explicitness, expressiveness, etc. This term was first put forward by French scholars Vinay and Darbelnet, who believe that explication is a stylistic translation skill and refers to the process of explicitly explaining information implied in the source language but inferred from the context or situation in the target language (Vinay \& Darbelnet, 1995). At the same time, Shuttleworth and Cowie put forward that explication refers to the target text expresses the information of the source text in a more obvious form, which means the translator adds explanatory phrases or conjunctions in the translation process to enhance the logic and ease of interpretation of the translation (Shuttleworth \& Cowie, 1997). Klaudy divides explication into four types: obligatory, optional, pragmatic and translation-inherent (Klaudy, 1998/2004). Based on the theoretical perspective of systemic functional linguistics, Huang Guowen and Yu Juan put forward that the common means of explication are mainly "addition, explanation and reconstruction" by designing the explication analysis framework of functional discourse analysis mode (Huang \& Yu, 2015). Pang Shuangzi and Wang Kefei elaborated the explication strategy and its application based on corpus research methods (Pang \& Wang, 2018). Pang Shuangzi and $\mathrm{Hu}$ Kaibao, focusing on the diachronic development of explication research and its concept, proposed that "both explicitness and implicitness should be emphasized, interlanguage and intralingual explication comparison should be strengthened, linguistics and translatology should be combined, diachronic investigation and motivation analysis should be added" so as to thoroughly study the explication (Pang \& Hu, 2019).

This paper takes the illogic expressions in construction texts as a starting point to analyze the application of explication strategy to make up for the broken logic chain during English translation.

\section{The Application of Explication Translation Strategy in English Translation of Construction Text}

In view of the ambiguity, vague expression and lack of logic in construction 
texts, which fails to achieve the effect of accurately conveying information, the application of explication strategy can highlight its strong applicability in guiding the English translation of such texts. Combined with the manifestation of illogic expressions in texts, this paper will elaborate the use of explication translation strategy to solve the problem from three specific aspects: explication of lexical process meaning, explication of sentence grammatical structure and explication of internal logical relationship.

\subsection{Explication of Lexical Process Meaning}

The accuracy of the concept depends on the accuracy of the words, which in turn depends on the amount of its meaning and its simultaneous relations in the sentence (Fang, 2011). The exact corresponding words can be used in the translation of technical words and semi-technical words. However, common words in construction texts have multiple meanings, thus its specialization during translation reflects the accurate meaning of words. Explication of lexical process meaning can help translators to choose the most suitable expression among various meanings, thus effectively avoiding the risk of illogic expressions.

Example 1

$\mathrm{ST}$ : 检查进度计划的落实情况, 及时调整劳动力和材料进场计划.

TT: Check the implementation of the progress plan and adjust the labor and material mobilization plan in time.

The word “进场” in the source text is a high-frequency word in construction texts as well as a professional word. It refers to the process of materials purchased by a certain project arriving at the construction site. The word "mobilization" used in the target text has a meaning of "become ready for service or action, to organize or assemble for a specific purpose" (Gao, 2005), which highlights the process meaning of the word “进场” and reflect the accuracy and professionalism of the text.

Example 2

ST: 下伏基岩埋深较浅为三叠系凝灰岩.

TT: The underlying bedrock with shallow buried depth is Triassic tuff.

The word “较浅” in the source text is used to describe the “埋深” which means "of little depth". According to the relation between words, the choice of the adjective “较浅” needs to indicate the distance between bedrock and soil surface and has the process meaning of measurement. The word "shallow" does not directly describe the meaning of "small", but highlights the meaning of the distance from the bottom to the top, which is consistent with the construction process.

\subsection{Explication of Grammatical Structure}

The integrity of grammatical elements is the basic requirement of the English language system. However, there are many non-subject sentences in construction texts, or sentences with the absence of subjects, which lead to the log- 
ic-chain breaks corresponding to the source texts in English translation. Based on this, it is necessary to supplement sentence grammatical components by adding the subject of the sentence and using the passive voice to avoid illogic expressions.

\subsubsection{Addition of Subject}

Directive statement is commonly used in the construction text, its directive meaning is usually presented in the form of non-subject sentences. In this case, finding out the implied logical relationship of the source text and determining the subject of the sentence are common methods to express grammatical elements in English translation.

Example 3

ST: 实现在权限控制的数据范围内, 对管网数据按照应用的要求进行查询.

TT: The system can query the pipe network data within the data range controlled by the authority according to the application requirements.

This sentence conforms to the Chinese expression habit and is a typical use of non-subject sentences. If translated it word for word, there will be grammatical errors due to the absence of subject, resulting in the breaking of logic chain. Adding the corresponding subject can make up the broken logic chain. According to the analysis of the source text, the predicate verb is the word “查询” in the source text, so the subject shall be a system that can query data, so the subject is determined to be "the system".

Example 4

ST: 路线布设需考虑避让沿线设施.

TT: Construction personnel should consider avoiding the facilities along the route when designing the route layout.

It is easy to mistake “路线布设” in the source text as the subject of the sentence when translating, resulting in illogic expressions. By analyzing the source text, this sentence should be understood as "avoid the facilities along the route when laying out the route". After further analysis, it is determined that "construction personnel" is the originator of the action of "route layout". Therefore, the subject "construction personnel" is added to make up for the broken logic chain.

\subsubsection{The Use of Passive Voice}

In addition to the above method of adding subject, the use of passive voice can also achieve the clarity of the texts. The use of passive voice is one of a means to manifest the commanded object and also a means to manifest the performer.

Example 5

ST: 控制不合格品或未纠正缺陷的分项工程不得进行下一步施工或交付.

TT: Prevent unaccepted products and defective sub-divisional projects from being constructed or delivered.

This sentence needs to emphasize that part of it is “不合格品或未纠正缺陷的 分项工程” in the source text, which lacks the subject, i.e. no performer. If the 
word “控制” in the source text is used to express command action and imperative sentences are used for English translation, it is inevitable that the real stressed object will be implied. Therefore, it is necessary to use the passive voice to make the real stressed part explicit.

Example 6

$\mathrm{ST}$ : 压实系数及相对密度采用灌砂法, 核子密度仪进行检测.

TT: The compaction coefficient and relative density shall be checked by the sand filling method and using the nuclear density meter.

The reason why the target text is prone to illogic expressions is different from the previous example. The use of non-subject sentence is not clear at a glance. The verb “采用” in the source text is likely to cause troubles during English translation. Through analysis, it is found that the sentence has no subject, and the word “采用” is not the predicate of “压实系数及相对密度”. Such a non-subject sentence also needs to adopt a passive voice to clarify the performer.

\subsection{Explication of Internal Logical Relationship}

Directive statement and short sentences are commonly used in the construction text for expressing information clearly. Based on the features, this part mainly expounds the methods for avoiding illogic expressions from the aspect of explicit logic relations between short sentences.

Example 7

ST: 项目正式开工前, 施工单位应全面做好施工准备工作, 准备工作包括 征地拆迁, 恢复中线, 三通(通水, 通电, 通路), 平整场地和临时工程等. 确保 施工队伍顺利进场.

TT: Prior to the formal commencement, the construction unit shall complete the construction preparation, including land requisition and relocation, restoration of central line, three supplies (water supply, power supply, road supply), site leveling and temporary works, etc. to ensure the smooth mobilization of construction team.

The text consists of several short sentences. “确保施工队伍顺利进场” is separated from the preceding sentence by a full stop indicates the division of meaning groups. However, the frequent occurrence of short sentences in the text will lead to fuzzy logical relations in English translation, which is easy to follow the sequence of the source text and lead to logic chain breaks. By analyzing the relationship between sentences, it is found that “确保施工队伍顺利进场” is the aim of the previous series of actions, so there is a progressive relationship between them. Connecting the two sentences with "to" to indicate the purpose makes up for the broken logic chain.

Example 8

ST: 受季节性降水影响, 每年 7 月份 11 月份雨季阶段, 湄公河水位上涨, $\mathrm{K} 50-\mathrm{K} 53, \mathrm{~K} 55-\mathrm{K} 56, \mathrm{~K} 60-\mathrm{K} 85+500$ 段路基两侧积水严重.

TT: During the rainy season from July to November of each year, there is serious water accumulation on both sides of the subgrade in K50-K53, K55-K56 
and K60-K85+500 sections due to the water level rising of the Mekong River.

This sentence is an objective description of the construction situation. It is mostly a short sentence with compact combination, but the logical relationship is implicit. It is found that the reason for “路基两侧积水严重” is “季节性降水 引起的水位上涨”, so there is a causal relationship between the two sentences. In English translation, this causal logic is manifested to achieve the purpose of accurate information transmission.

\section{Conclusion}

This paper analyzes the causes of illogic expressions and its manifestations at lexical, syntactical and discourse level. Different thinking modes in Chinese and English lead to the illogic expression in Chinese to English translation. Influenced by Chinese philosophy, Chinese language tends to be synthetic and implicit. On the contrary, English language is analytical with strict rules in word order, syntax. Neglecting such differences will result in illogical expressions in Chinese to English translation of construction text. Thus, this paper illustrates the application of explication translation strategy including the explication of lexical process meaning, explication of grammatical structure. What's more, this paper provides a reference for the translation of construction documents of various Sino-foreign cooperative construction projects, which has practical significance for the development of construction activities.

\section{Conflicts of Interest}

The authors declare no conflicts of interest regarding the publication of this paper.

\section{References}

Duan, Y. (2004). Seeing the Inclusiveness, Abstraction and Deviation of Language and Logic from a Sample of Logical Biases. Journal of Jiangxi Institute of Education (Social Science), No. 2, 30-32.

Fang, M. (2011). English Science and Technology Style: Paradigm and Translation (pp. 37-38). Beijing: National Defense Industry Press.

Gao, L. (2005). English-Chinese Dictionary (p. 631). Beijing: Foreign Languages Press.

Gu, Q. (2015). Explicitization of Implicit Logic in English-Chinese Sci-Tech Translation. Chinese Science and Technology Translation, 28, 7-10.

Huang, G., \& Yu, J. (2015). Translational Explicit Research from the Perspective of Functional Discourse Analysis. Foreign Language and Foreign Language Teaching, No. 3, 41-47.

Klaudy, K. (1998/2004). Explication. In M. Baker (Ed.), Routledge Encyclopedia of Translation Studies (p. 81). Shanghai: Shanghai Foreign Language Education Press.

Li, C. (2012). Non-Literary Translation Theory and Practice (2nd ed., pp. 37-38). Shanghai: Chinese Translation Publishing House.

Lian, S. (2010). English-Chinese Comparative Study (pp. 74, 78). Beijing: Higher Education Press. 
Pang, S., \& Hu, K. (2019). Research on Explicit Problems in Translational Commonality. Modern Foreign Language, No. 1, 1-10.

Pang, S., \& Wang, K. (2018). Language Contact Research through Translation: The Diachronic Influence of the "Explicit" Feature of Translated Text on Native Text. Foreign Language Teaching and Research, 50, 253-267+320-321.

Shuttleworth, M., \& Cowie, M. (1997). Dictionary of Translation Studies (p. 55). Manchester: St. Jerome Publishing.

Vinay, J. P., \& Darbelnet, J. (1995). Comparative Stylistics of French and English: A Methodology for Translation (p. 342). Amsterdam/Philadelphia, PA: John Benjamins Publishing Company. https://doi.org/10.1075/btl.11

Wu, D. (2015). Logical Offset in Scientific English Articles and Its Chinese Translation Processing. Chinese Science and Technology Translation, 28, 1-4.

Xi, C. (2008). The Expression of Implicit Logical Relationship in Chinese-English Translation. Chinese Science and Technology Translation, No. 4, 5-9. 